\title{
Optimization of Damper Top Mount Characteristics to Improve Vehicle Ride Comfort and Harshness
}

\author{
Mina M. S. Kaldas, Kemal Çalışkan, Roman Henze, and Ferit Küçükay \\ Institute of Automotive Engineering (IAE), TU Braunschweig, Germany \\ Correspondence should be addressed to Mina M. S. Kaldas; m.kaldas@tu-bs.de
}

Received 31 January 2013; Accepted 2 September 2013; Published 13 March 2014

Academic Editor: Peijun Xu

Copyright (C) 2014 Mina M. S. Kaldas et al. This is an open access article distributed under the Creative Commons Attribution License, which permits unrestricted use, distribution, and reproduction in any medium, provided the original work is properly cited.

\begin{abstract}
A novel optimization technique for optimizing the damper top mount characteristics to improve vehicle ride comfort and harshness is developed. The proposed optimization technique employs a new combined objective function based on ride comfort, harshness, and impact harshness evaluation. A detailed and accurate damper top mount mathematical model is implemented inside a validated quarter vehicle model to provide a realistic simulation environment for the optimization study. The ride comfort and harshness of the quarter vehicle are evaluated by analyzing the body acceleration in different frequency ranges. In addition, the top mount deformation is considered as a penalty factor for the system performance. The influence of the ride comfort and harshness weighting parameters of the proposed objective function on the optimal damper top mount characteristics is studied. The dynamic stiffness of the damper top mount is used to describe the optimum damper top mount characteristics for different optimization case studies. The proposed optimization routine is able to find the optimum characteristics of the damper top mount which improve the ride comfort and the harshness performances together.
\end{abstract}

\section{Introduction}

Damper top mounts are used in the vehicles not only to provide ideal Noise-Vibration-Harshness $(\mathrm{NVH})$ performance but also to improve ride comfort, driving safety, and handling. The ride comfort and harshness can be considered as the vibration response of the vehicle body at different frequency ranges. Vehicle ride comfort can be evaluated by using vertical acceleration of the body up to $20 \mathrm{~Hz}$ while the harshness can be considered as the body vertical acceleration in the frequency range over $20 \mathrm{~Hz}$ until $100 \mathrm{~Hz}$ [1]. Another type of the vehicle harshness is the impact harshness (IH) which also affects the subjective impression of ride comfort. This type of harshness involves the vibration response of the vehicle which is referred to as IH events [2-5].

The driver and the passengers are always in contact with different parts of the vehicle chassis during the operation of the vehicle. Therefore, it is expected that reducing the acceleration response of the vehicle body will improve ride comfort and harshness. Some previous studies have shown that the ride comfort and harshness performance of the vehicle can be improved by optimizing the characteristics of the suspension system components [5-13].

A numerical procedure for finding the optimum values of the vehicle suspension system parameters has been studied by Pintado and Benitez [6]. The vehicle is modeled as a dynamic system composed of rigid bodies, linear springs, and dampers, which can be subjected to road irregularities together with centrifugal and braking accelerations. The sequential linear programming technique is used to minimize the acceleration peaks at a selected design point in the vehicle. The results show that the number of restrictions should be reduced in order to speed up the optimization process. As an extension of this study, Del Castillo et al. [7] developed an optimization code that provides values corresponding to the characteristics of masses, dampers, and springs which minimize the objective function for a defined excitation. Sequential linear programming is used for 
the optimization by iteratively applying the simplex algorithm. The model response is obtained in the frequency domain and the objective function used quantifies the vehicle comfort level. In the optimization problem, the objective function and restrictions are adapted according to the type of excitation. The main contributions are the method used for dealing with the restrictions due to the elastic linkages and the results regarding the little influence of tire stiffness on the passenger comfort and loading damage.

An efficient methodology for the determination of the gradient information, while performing gradient based optimization of an off-road vehicle's suspension system, has been proposed by Thoresson et al. [10]. The methodology is applied to a computationally expensive, nonlinear vehicle model that exhibits severe numerical noise. A recreational off-road vehicle is modeled in MSC.ADAMS and coupled to MATLAB. The successive approximation method, Dynamic-Q, is used for the optimization of the spring and damper characteristics. Optimization is performed for both ride comfort and handling. The objective function value is determined using the computationally expensive numerical simulation. A nonlinear pitch-plane model is used to obtain the gradient information for the ride comfort optimization, while a nonlinear four-wheel model including roll degree of freedom is used in the handling optimization. The models are validated using experimental data. The simplified vehicle models exhibit significantly less numerical noise than the full vehicle simulation model and require significantly less computational time. The optimization results of this work have been published in [11]. The results show that the proposed methodology is an efficient alternative to the evolutionary techniques for the optimization of the suspension characteristics of a vehicle. The undesirable effects associated with the noise in the gradient information are effectively reduced by using the simplified models. Substantial benefits have been achieved in terms of computational time needed to reach the optimum solution.

The impact harshness performance of a vehicle is as important as the ride comfort and handling. In a recent study, Aydın and Ünlüsoy [5] developed a parameter optimization methodology to improve impact harshness (IH) of road vehicles, which involves the use of design of experiments (DoE) method together with the response surface methodology. The design parameters of the suspension system affecting the IH of the vehicle are optimized. The results indicate that the optimized suspension parameters are capable of improving IH performance of the full vehicle ADAMS model by minimizing the longitudinal and vertical acceleration responses. It is relatively easier and cost effective to change the compliance of the damper top mounts compared to changing any other suspension component characteristics to improve the vehicle ride comfort and harshness performance $[3,4$, $12,14]$. On the other hand, for analyzing the influence of top mount characteristics on the vehicle ride comfort and harshness, a detailed and accurate mathematical damper top mount model is required. In another study [15], a detailed damper top mount model based on the restoring force mapping technique has been presented. The mathematical model parameters of different commercial damper top mounts are identified using experimental data. The presented damper top mount model consists of three elements, which are the nonlinear elastic, the nonlinear friction, and the nonlinear viscous elements. The amplitude dependency of the top mount characteristics is modeled using the friction element and the elastic element, while the frequency dependency of the top mount is modeled using the restoring force mapping technique. Furthermore, a new procedure is proposed for the identification of the model parameters, which is based on a two-stage optimization routine where two sets of measurement data from the amplitude and frequency dependent tests are used. The model is validated by comparing the measured and simulated forces for three different commercial damper top mounts. Furthermore, the proposed top mount model is found to be superior to the existing rubber isolator models. A parametric study using this mathematical damper top mount model is presented in [16] which analyses the influence of the damper top mount characteristics on the ride comfort and harshness performance of a vehicle. All top mount parameters investigated in this work have been shown to have remarkable effects on either one or both of the ride comfort and harshness performances of the vehicle. Therefore, it is concluded that significant improvements can be achieved through proper adjustment of the damper top mount characteristics.

In this study, a new optimization technique for damper top mount characteristics is presented to improve the ride comfort and harshness performance of a vehicle. A new combined objective function involving ride comfort, harshness, and impact harshness evaluation is proposed, and it is used within an evolutionary optimization routine. The detailed mathematical damper top mount model of [15] is implemented inside a validated quarter vehicle model to provide a proper simulation environment for the optimization study. The influence of the ride comfort and harshness weighting parameters of the proposed objective function on the damper top mount characteristics is studied. The optimal dynamic stiffness of the damper top mount is calculated for different optimization goals. The ride comfort and harshness are evaluated by analyzing the body acceleration in different frequency ranges. In addition to this, top mount deformation is considered as a penalty factor for the system performance.

\section{Vehicle Model}

In this study, a generic quarter vehicle suspension model including a detailed damper top mount model is used. The vehicle is modeled as a two-degree-of-freedom system consisting of two masses which represent the body and wheel. The damper and top mount weights are neglected. The suspension between body mass and wheel mass is modeled using a linear spring and a viscous damper in series with a rubber top mount as shown in Figure 1. The nonlinear characteristics of the damper and the top mount are taken into account. The tire is modeled as a linear spring and viscous damper and a point contact is assumed between the road and the tire. 


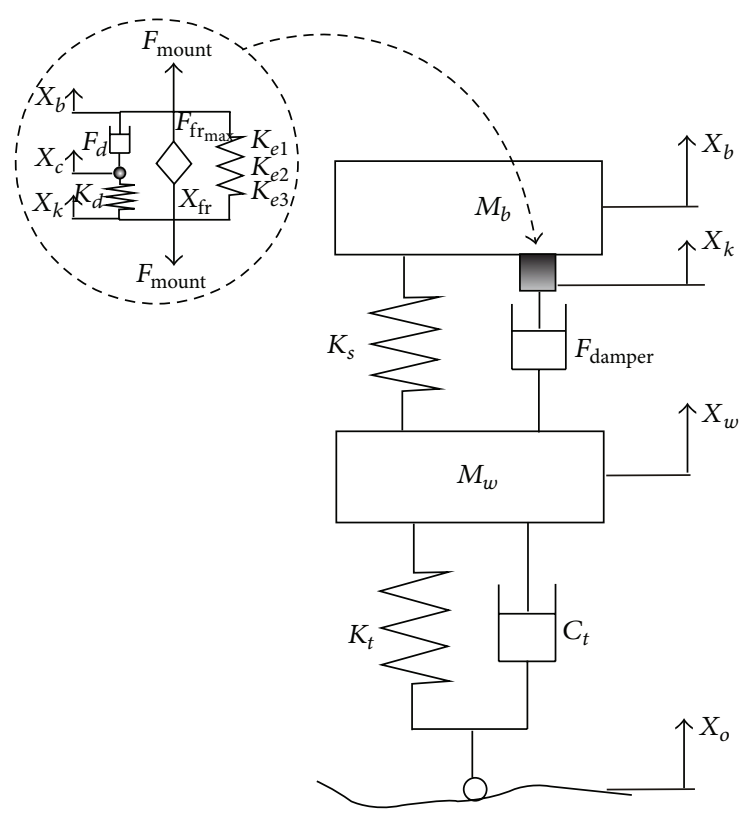

FIGURE 1: Quarter vehicle model.

The dynamic equations of motion for the quarter vehicle model are written as follows:

$$
\begin{aligned}
& M_{b} \ddot{X}_{b}=-K_{s}\left(X_{b}-X_{w}\right)-F_{\text {mount }}, \\
& M_{w} \ddot{X}_{w}=-K_{t}\left(X_{w}-X_{o}\right) \\
& -C_{t}\left(\dot{X}_{w}-\dot{X}_{o}\right)+K_{s}\left(X_{b}-X_{w}\right)+F_{\text {damper }}, \\
& F_{\text {damper }}=f\left(\left(\dot{x}_{k}-\dot{x}_{w}\right),\left(\ddot{x}_{k}-\ddot{x}_{w}\right)\right) \text {, } \\
& F_{\text {mount }}=F_{\text {elastic }}+F_{\text {friction }}+F_{\text {viscous }} \text {, } \\
& F_{\text {elastic }}=K_{e 1}\left(x_{b}-x_{k}\right) \\
& +K_{e 2}\left(x_{b}-x_{k}\right)^{2}+K_{e 3}\left(x_{b}-x_{k}\right)^{3}, \\
& =\left\{\begin{array}{cr}
F_{\mathrm{fr}_{s}} & \text { if } x=x_{s} \\
F_{\mathrm{fr}_{s}}+\frac{x-x_{s}}{x_{\mathrm{fr}_{\mathrm{r}}(1-\delta)+\left(x-x_{s}\right)}} & \\
\times\left(F_{\mathrm{fr}_{\text {max }}}-F_{\mathrm{fr}_{s}}\right) & \text { if } x>x_{s} \\
F_{\mathrm{fr}_{s}}+\frac{x-x_{s}}{x_{\mathrm{fr}_{\mathrm{r}}(1+\delta)-\left(x-x_{s}\right)}\left(1+F_{\mathrm{fr}_{s}}\right)} & \\
\times\left(F_{\mathrm{fr}_{\text {max }}}+F_{\mathrm{fr}_{s}}\right. & \text { if } x<x_{s},
\end{array}\right. \\
& F_{\text {viscous }}=f_{\text {damper }}\left(\left(\dot{x}_{b}-\dot{x}_{c}\right),\left(x_{b}-x_{c}\right)\right) \text {, }
\end{aligned}
$$

where $F_{\text {damper }}$ stands for the damping force which is a function of the damper velocity and acceleration and $F_{\text {mount }}$ is the overall damper top mount force. $F_{\text {elastic }}, F_{\text {friction }}$, and $F_{\text {damping }}$ are the elastic, friction, and viscoelastic forces of the top mount model [15]. The body, damper top mount and wheel displacements, and the road input, $X_{b}, X_{k}, X_{w}$, and
TABLE 1: Quarter vehicle model parameters.

\begin{tabular}{lcc}
\hline Parameter & Value & Unit \\
\hline Body mass & 270.8 & $\mathrm{~kg}$ \\
Wheel mass & 46.5 & $\mathrm{~kg}$ \\
Spring stiffness & 32 & $\mathrm{kN} / \mathrm{m}$ \\
Tire stiffness & 320 & $\mathrm{kN} / \mathrm{m}$ \\
Tire damping & 200 & $\mathrm{Ns} / \mathrm{m}$ \\
\hline
\end{tabular}

$X_{o}$, are defined with respect to the inertial frame. The quarter vehicle parameters used in this study are listed in Table 1.

2.1. Damper Top Mount Model. A detailed damper top mount model developed by the authors is used for the optimization analysis in this study [15]. This model employs a nonlinear spring pot coupled in parallel with a nonlinear smooth friction element and a nonlinear elastic spring. The layout of the model is shown in Figure 2. The structure of the mount model accounts for both amplitude and frequency dependent characteristics of the rubber top mounts. The amplitude dependency of the model is provided by the nonlinear elastic element and the nonlinear smooth coulomb friction element, while the frequency dependency is taken into account by using a linear spring and a nonlinear damper in series. The nonlinear damping element is modeled by using the restoring force mapping method. The total restoring force of the top mount model is the sum of the forces from each component of the model as given with (4). The sum of the elastic, friction, and viscoelastic forces at a particular time step is based on a superposition assumption which suggests that the forces develop independently. The model is simplified by assuming that the amplitude dependent characteristics are independent 


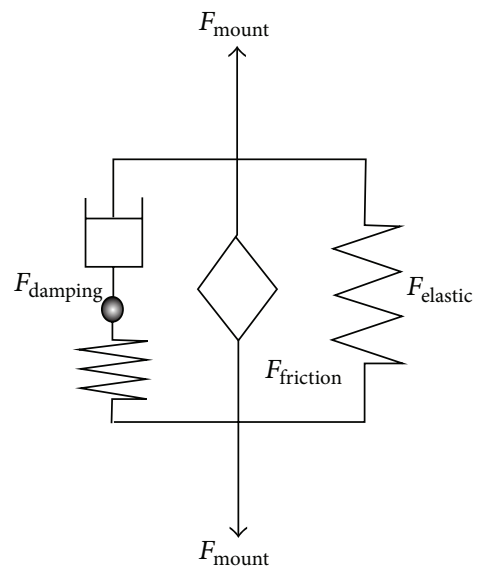

Figure 2: Damper top mount model.

of the excitation frequency and the frequency dependent characteristics are independent of the excitation amplitude.

As shown in Figure 3, the simulated forces of the damper top mount model are in good agreement with the measured top mount forces. Obviously, the use of the restoring force mapping technique in the modeling of the viscous element improves the accuracy in the overall top mount model. This technique enables accurate simulation of the frequency dependent characteristics of the damper top mounts since it can represent the viscous force at all excitation frequencies and amplitudes.

The dynamic stiffness is a commonly used rubber mount characteristic, which describes the change of rubber mount behaviour with the excitation frequency. A comparison between the measured and the simulated dynamic stiffness of the damper top mount is shown in Figure 4. The dynamic stiffness of the damper top mount increases gradually with the increase in the excitation frequency. The stiffness values obtained from the simulation model fit well with those obtained from the measurements. A detailed description of the damper top mount model has been presented in [15] together with the model verification tests, the restoring force mapping technique, and the model parameter identification process.

2.2. Combined Top Mount-Damper Model. The detailed top mount model presented in the previous section can be used to analyze the effect of damper top mount characteristics on the vertical dynamics of a vehicle. However, since the damper top mount operates in series to the damper, that is, transmits the damper force to chassis, the damper top mount model should be combined with a detailed damper model. Therefore, in the quarter vehicle model, the detailed top mount model is used together with the IAE nonlinear damper model [17]. Figure 5 presents the layout of the combined top mountdamper model. The force generated by the damper is equal to the force generated by the damper top mount while the displacements of each are different. In the quarter vehicle model, the damper model is used to calculate the damping force applied to the body and wheel, and an inverse form of the damper top mount model is used to provide the relative displacement information required by the damper model.

The damper top mount and the combined top mountdamper models are verified through physical tests performed on a hydraulic component test rig. Figures 6(a) and 6(b) present the component test rig setup for the damper top mount and the combined damper top mount assembly.

The time history of the simulated and the measured damper forces and the damper top mount displacements for a stochastic excitation are plotted in Figures 7(a), 7(b), $7(\mathrm{c})$, and $7(\mathrm{~d})$ for two different time intervals. The results indicate that both the damper force and the damper top mount displacement can be simulated accurately by using the proposed damper top mount model together with the detailed damper model. This demonstrates that the combined top mount-damper model enables accurate simulation of the damper strut forces inside a vehicle dynamics model [16].

2.3. Verification of the Vehicle Model. The quarter vehicle simulation model is validated through laboratory tests performed using the quarter vehicle test rig shown in Figure 8(a). This test rig is a practical realization of the often theoretically considered quarter vehicle, consisting of the sprung and unsprung masses as well as suspension components such as subframe, linkages, spring, damper, and rubber mounts. A hydraulic cylinder is used to excite the quarter vehicle test rig with harmonic inputs or measured road profiles.

A comparison of the measured and simulated transfer function magnitudes between body and road accelerations, which are obtained by using a real measured road profile as the excitation, is presented in Figure 8(b). It is shown that the quarter vehicle model is capable of simulating the body bounce response of the quarter vehicle test rig, especially in the low frequency range. The difference between the measured and the simulated transfer function magnitudes arises due to the structural vibrations of the test rig frame and the friction in the sliders, both of which are not included in the vehicle model. 


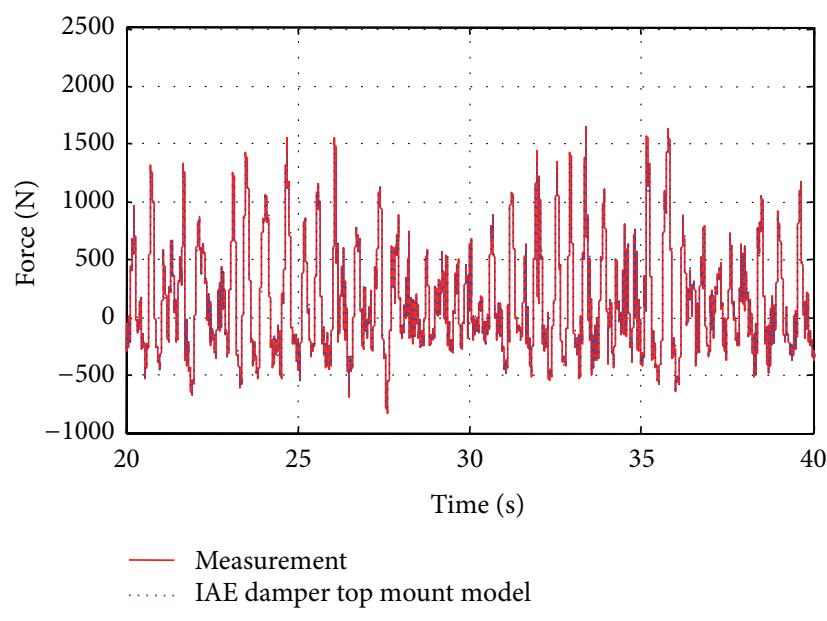

(a)

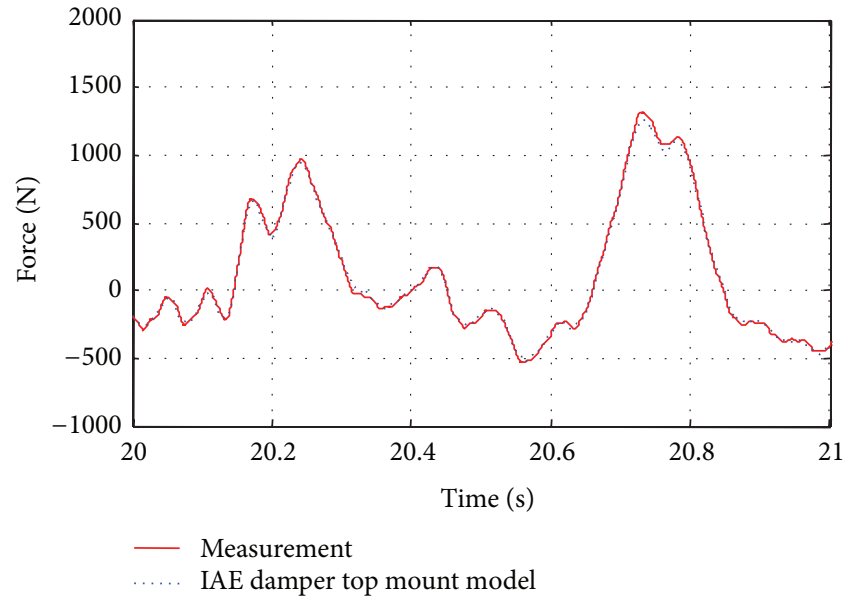

(b)

FIGURE 3: Measured and simulated time histories of the damper top mount force for a stochastic excitation.

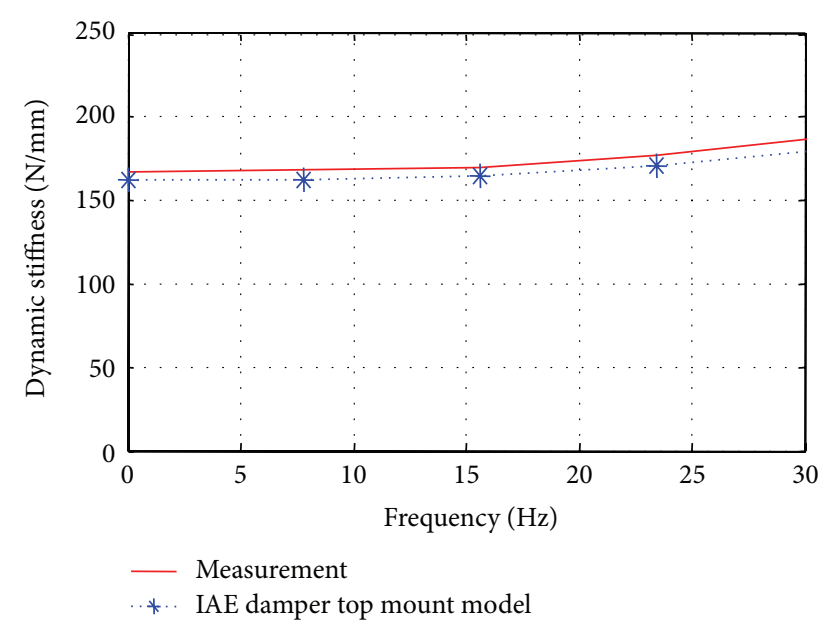

Figure 4: Measured and simulated damper top mount dynamic stiffness.

\section{Damper Top Mount Optimization}

3.1. Road Profile Inputs. Two types of road inputs are used for the ride comfort and harshness optimization analysis. The first type of input is a real road profile selected from the road profile measurement database available of the IAE [18]. The real road profile used for the optimization analysis is shown in Figure 9(a).

The IH events are usually evaluated under specific forward velocities without applying any steering input. In order to evaluate IH performance of a vehicle through computer analysis, the mathematical model of the vehicle can be simulated using a triangle road cleat as the road input. Typical forward speed range for the analysis of $\mathrm{IH}$ events is around $60 \mathrm{kph}$ [5]. The triangle cleat used for the optimization analysis of $\mathrm{IH}$ event has a height of $30 \mathrm{~mm}$ and a length of $400 \mathrm{~mm}$ as illustrated in Figure 9(b) [4].
3.2. Damper Top Mount Optimization Methodology. As a preparation to the optimization analysis, the authors have performed a parametric study to analyze the influence of the top mount characteristics on vehicle ride comfort and harshness [16]. The parameters of the damper top mount model are varied proportionally to the values identified from the component tests. It is shown that all investigated top mount parameters $\left(K_{e 1}, K_{e 2}, K_{e 3}, F_{\mathrm{fr}_{\text {max }}}\right.$, and $\left.F_{d}\right)$ have visible effects on both or one of the ride comfort and harshness of the vehicle model used. The parametric study suggests that both ride comfort and harshness of a vehicle can be improved significantly through proper adjustment of damper top mount characteristics.

Regarding the effect of damper top mount stiffness on vehicle vertical dynamics, a conflict exists between the low frequency ride comfort and the high frequency harshness objectives. The results of the parametric study showed that high top mount stiffness is preferable for improved ride comfort at low frequencies while lower stiffness values provide improved harshness performance during high frequency excitations. As a result of this fact, the dynamic stiffness, which describes the stiffness of the top mount as function of the excitation frequency, can be regarded as the most important characteristic of a top mount. A similar conflict has also been observed during the impact harshness analysis. In order to reduce the magnitude of the first peak of the body acceleration after a triangle cleat input, the top mount stiffness should be low; however, secondary peaks attain higher values in this case.

Following the concluding remarks of the parametric analysis in [16], an optimization routine with a combined objective function is developed in this study. The ride comfort, harshness, and impact harshness performances of the vehicle have been considered in the proposed objective function. As shown in (4), the objective function is the sum of the cost function of ride comfort and harshness (R\&H) performance in frequency domain and the cost function of the impact harshness (IH) performance in time domain. 


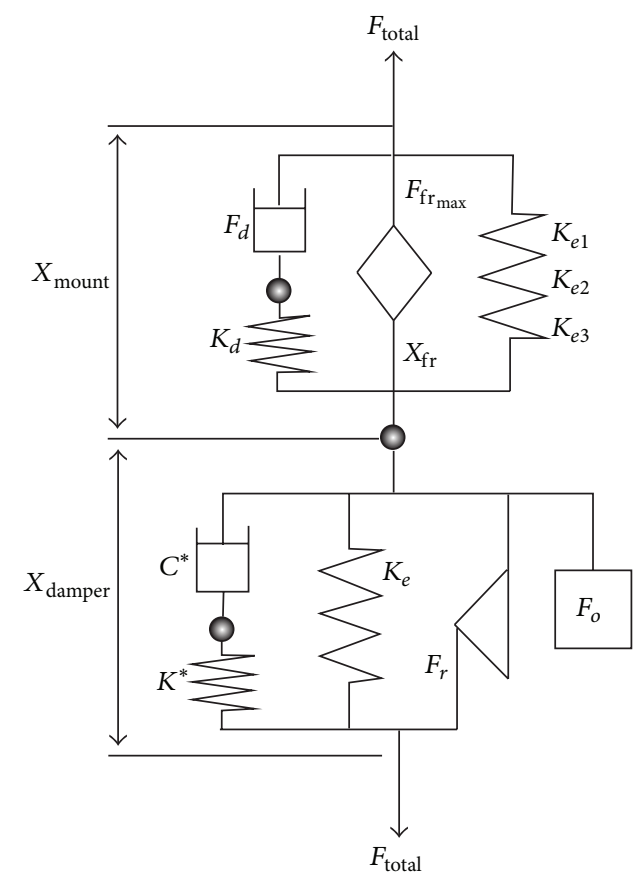

FIGURE 5: Combined top mount and damper model.

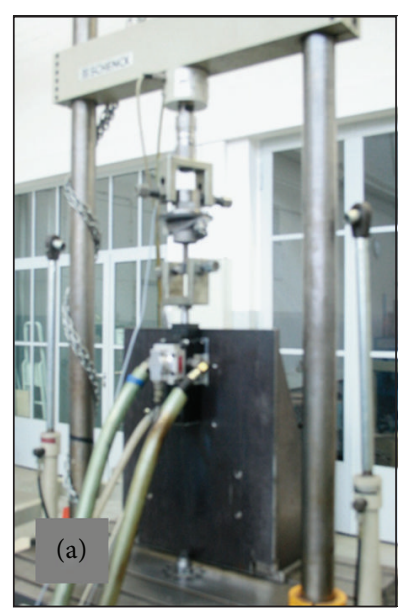

(a)

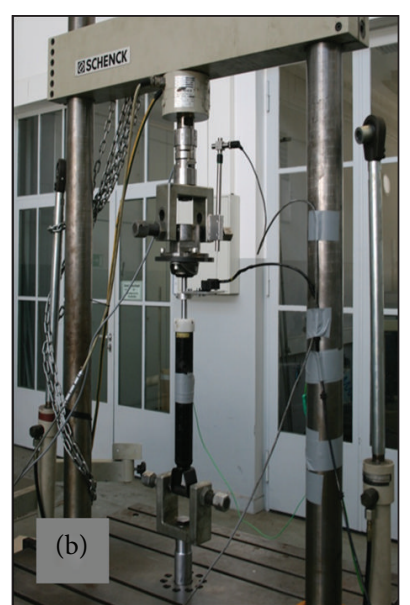

(b)

FIgURE 6: Components test rig setup: (a) top mount and (b) top mount together with damper.

Three frequency ranges have been defined for the evaluation of the ride comfort and harshness. The ride comfort frequency range (R1) covers the frequencies from $0 \mathrm{~Hz}$ to $20 \mathrm{~Hz}$, while the harshness frequency ranges ( $\mathrm{H} 1$ and $\mathrm{H} 2)$ cover frequencies from $20 \mathrm{~Hz}$ to $50 \mathrm{~Hz}$ and from $50 \mathrm{~Hz}$ to $80 \mathrm{~Hz}$, respectively. The cost function for the ride comfort and harshness $(\mathrm{R} \& \mathrm{H})$ performance (9) includes the sum of the power spectral density (PSD) of the body acceleration in the ride comfort frequency range (R1) and in the harshness frequency ranges ( $\mathrm{H} 1$ and $\mathrm{H} 2)$. The harshness frequency range from 20 to $80 \mathrm{~Hz}$ is divided into two subranges since the acceleration magnitudes in these two frequency ranges are significantly different from each other. In addition to the body acceleration, the sum of the PSD of the damper top mount deformation in the overall ride comfort and harshness frequency range from $0 \mathrm{~Hz}$ to $80 \mathrm{~Hz}$ is considered in the $\mathrm{R} \& \mathrm{H}$ cost function. The cost function of the impact harshness (IH) performance is the sum of the first peak-to-peak values of the 


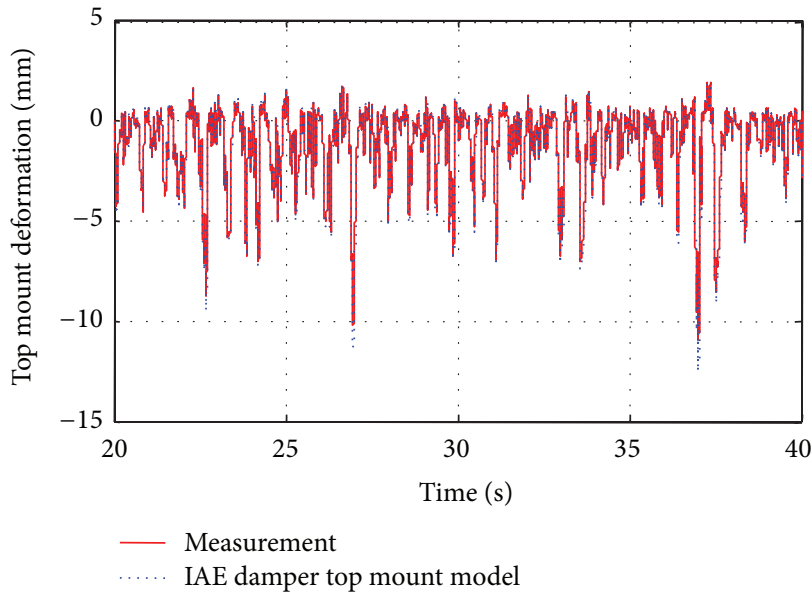

(a)

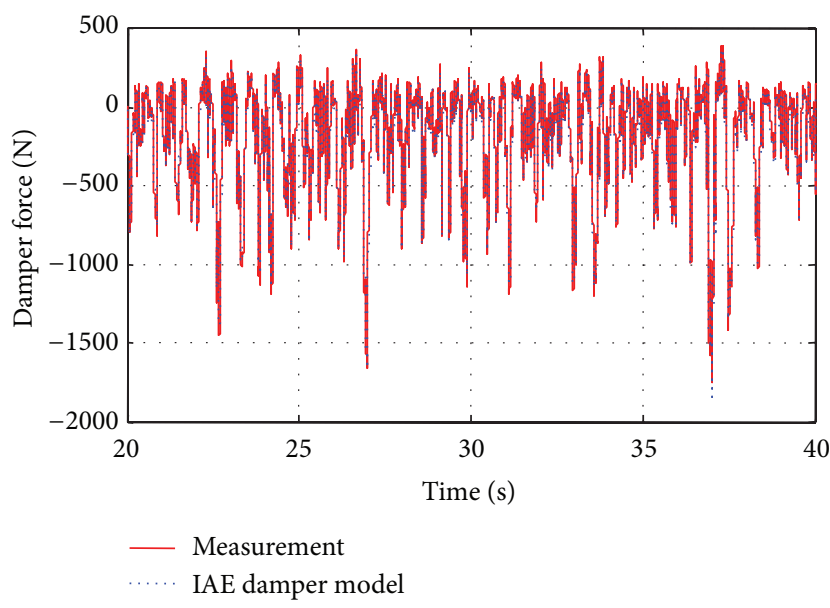

(c)

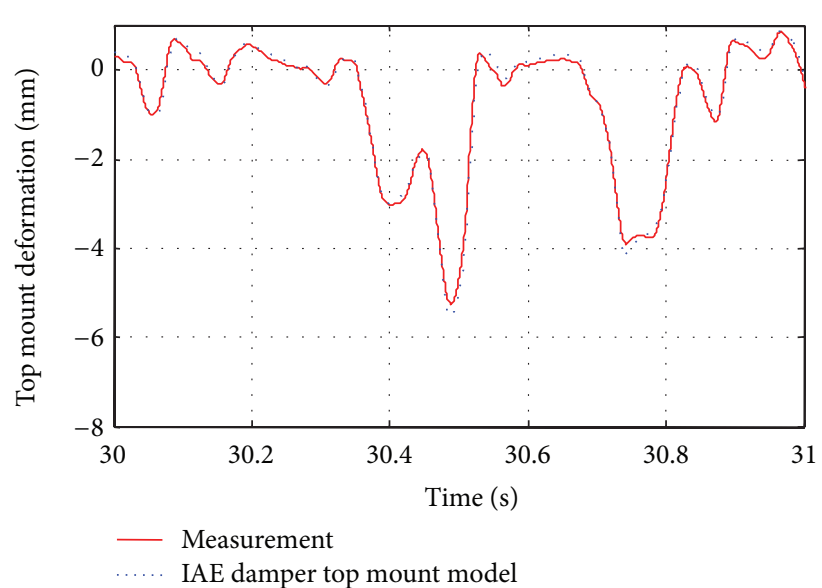

(b)

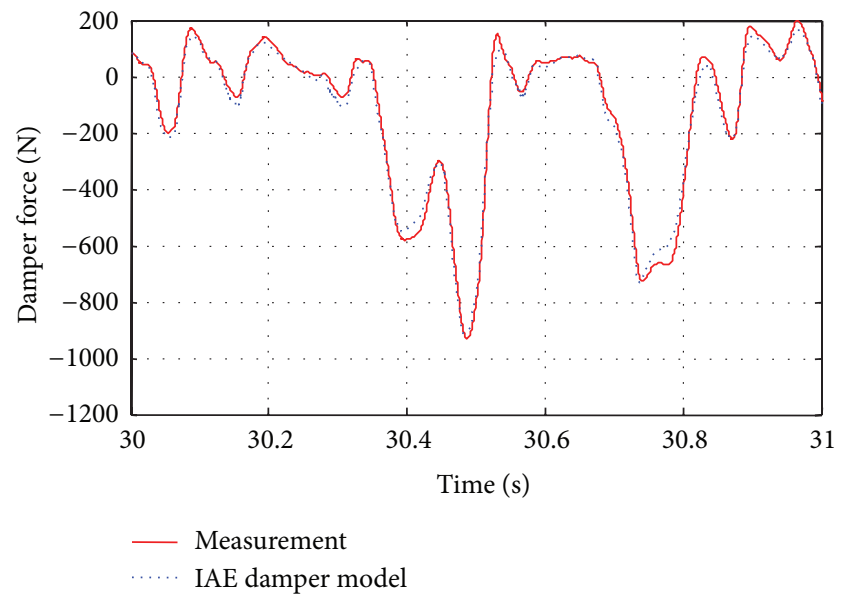

(d)

FIGURE 7: Comparison of measured and simulated damper top mount behavior: (a)-(b) top mount displacement and (c)-(d) damper force.
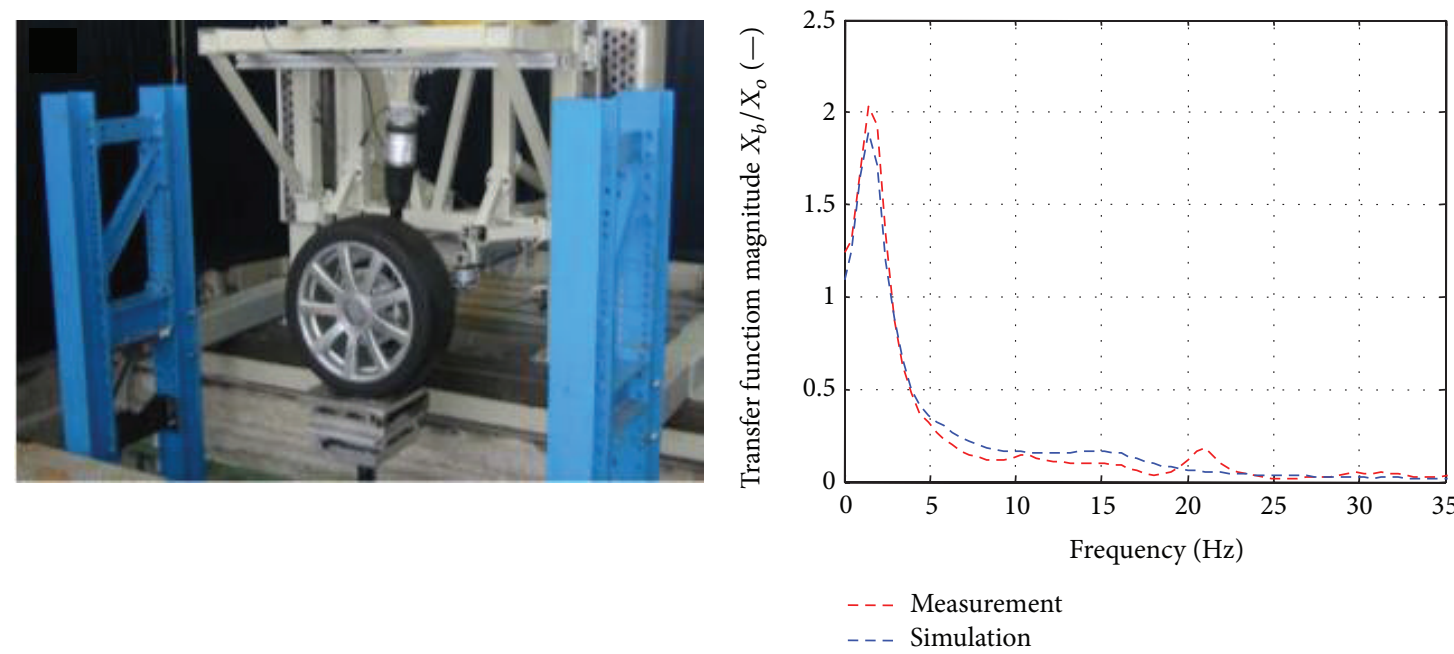

(a)

(b)

FIGURE 8: (a) Quarter vehicle test rig at IAE and (b) quarter vehicle model verification. 


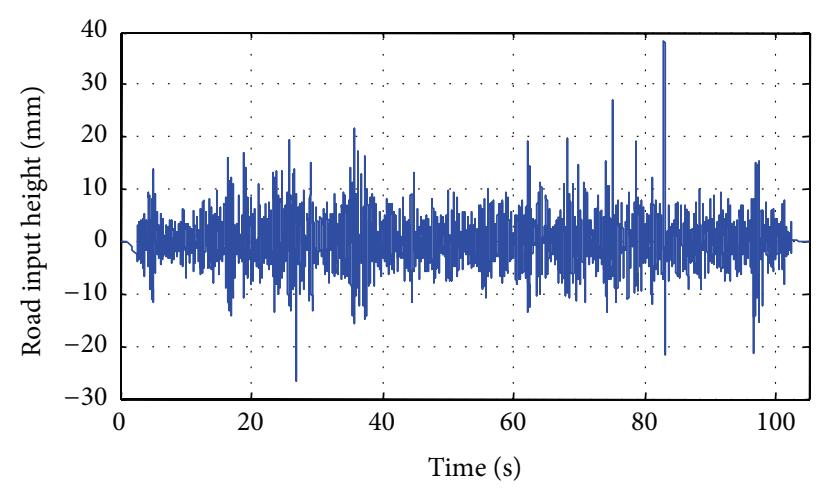

(a)

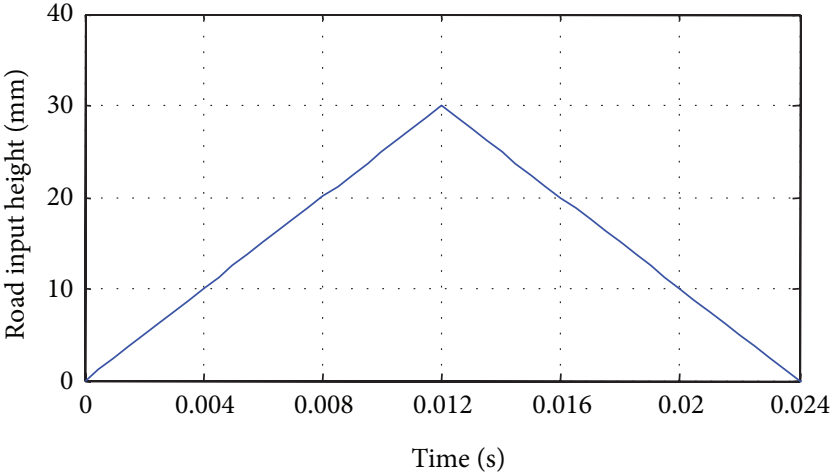

(b)

FIgURE 9: Road inputs: (a) random road and (b) triangle cleat.

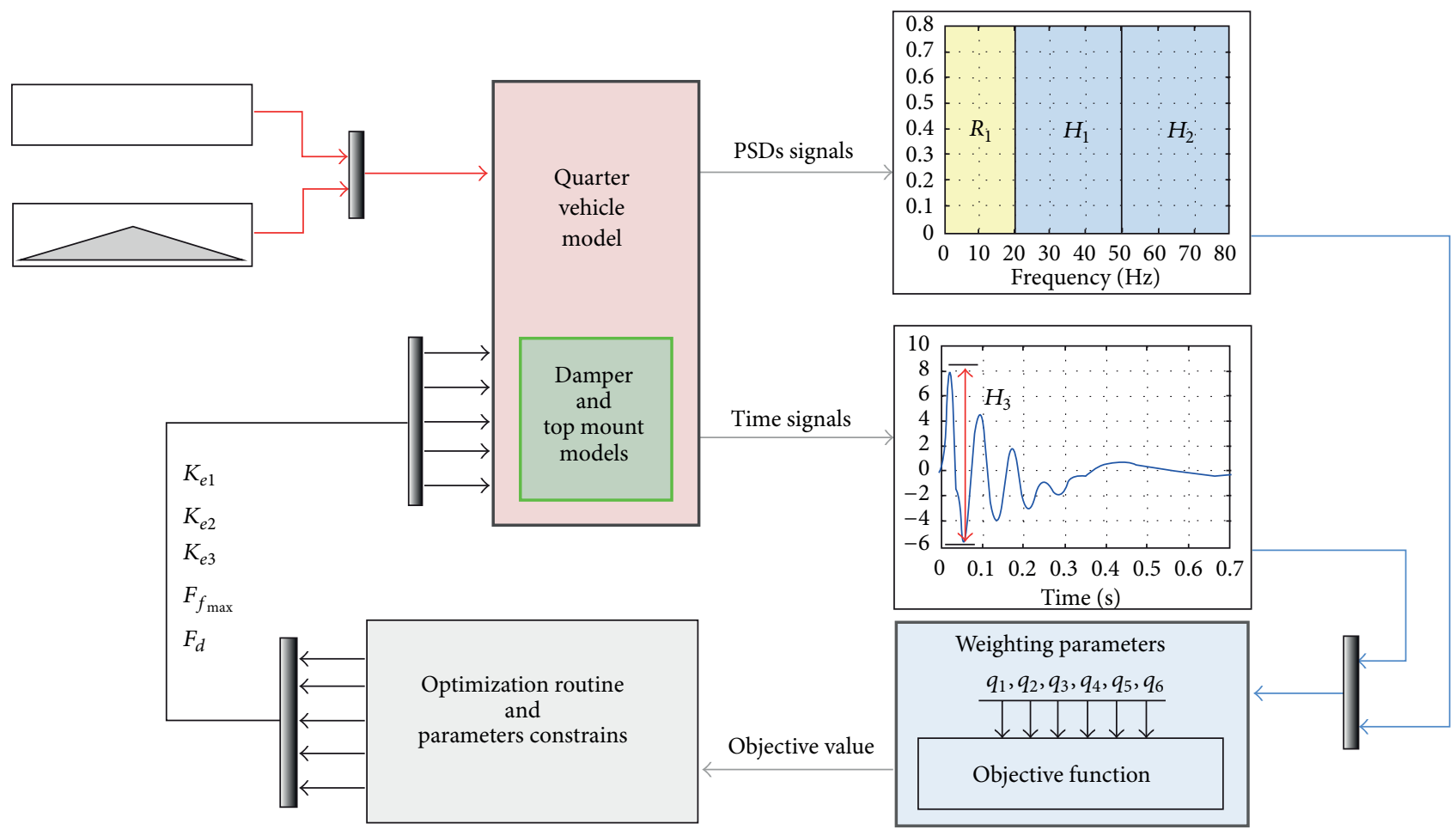

FIGURE 10: The proposed optimization process for damper top mount characteristics.

body vertical acceleration (H3) and the damper top mount deformation in the time domain, as shown in (10):

$$
\text { Objective }_{\text {total }}=\text { Cost }_{\mathrm{R} \& \mathrm{H}}+\operatorname{Cost}_{\mathrm{IH}} \text {, }
$$

$$
\begin{aligned}
\operatorname{Cost}_{\mathrm{R} \& \mathrm{H}}= & q_{1}^{*} \sum_{0 \mathrm{~Hz}}^{20 \mathrm{~Hz}} s_{\ddot{X}_{b}}+q_{2}^{*} \sum_{20 \mathrm{~Hz}}^{50 \mathrm{~Hz}} s_{\ddot{X}_{b}} \\
& +q_{3}^{*} \sum_{50 \mathrm{~Hz}}^{80 \mathrm{~Hz}} S_{\ddot{X}_{b}}+q_{4}^{*} \sum_{0 \mathrm{~Hz}}^{80 \mathrm{~Hz}} S_{X_{b}-X_{k}}, \\
\operatorname{Cost}_{\mathrm{IH}}= & q_{5}^{*}\left(\ddot{\mathrm{X}}_{b_{\max 1}}-\ddot{\mathrm{X}}_{b_{\min 1}}\right) \\
& +q_{6}^{*}\left(\left(\mathrm{X}_{b}-\mathrm{X}_{k}\right)_{\max }-\left(\mathrm{X}_{b}-\mathrm{X}_{k}\right)_{\min }\right) .
\end{aligned}
$$

The parameters $q_{1}^{*}, q_{2}^{*}, q_{3}^{*}, q_{4}^{*}, q_{5}^{*}$, and $q_{6}^{*}$ in (5) and (6) are used to adjust the relative importance of the ride comfort and harshness performance in the objective function. It should be noted that the parameters $q_{1, \ldots, 6}^{*}$ include both the weighting parameters $q_{i}$ which describe the relative importance of the performance measures used in the objective function and the normalization factors $q_{i}^{n}$ which account for the nominal values of the these measures. The normalization factors $q_{i}^{n}$ are obtained through simulation of the vehicle model with the experimentally identified rubber mount parameters:

$$
q_{i}^{*}=\frac{q_{i}}{q_{i}^{n}} \quad \text { for } i=1, \ldots, 6
$$


As the first stage of the optimization analysis, the influence of the weighting parameters of the proposed objective function on the optimum damper top mount characteristics, and consequently on the trade-off between the vehicle ride comfort and harshness performance, is investigated. The aim of the optimization process is to improve the ride comfort and harshness by reducing the vertical acceleration of the vehicle body at different frequency ranges, while keeping the damper top mount deformation within the allowable limits. The proposed optimization routine is shown in Figure 10. During the optimization process, the quarter vehicle model with a set of rubber mount parameters is simulated using the real road and triangle road cleat profiles. The simulation outputs of interest, the body acceleration and the damper top mount deformation, are used to calculate the PSD curves and peak-to-peak values, which are required by the proposed objective function. The Genetic Algorithm (GA) optimization routine is used to determine the optimum damper top mount characteristics which minimize the defined objective function.

In the optimization analysis, the weighting parameters of the proposed objective function $q_{1}, q_{2}, q_{3}$, and $q_{5}$ are tuned to emphasize relative importance of the vehicle ride comfort and harshness, while the weighting parameters $q_{4}$ and $q_{6}$ are kept constant at 1 . The optimization study is performed according to the following strategy.

(1) Ride Comfort Optimization. The objective is to obtain the optimum damper top mount characteristics that improve ride comfort only. In this case, the relative importance of vehicle harshness performance is considered as $0 \%$ by setting the weighting parameters $q_{2}, q_{3}$, and $q_{5}$ as 0 . The relative importance of the ride comfort is increased gradually by changing the value of the weighting parameter $q_{1}$ stepwise between 0.2 and 1 .

(2) Harshness Optimization. In this case, the optimum damper top mount characteristics are expected to provide the best harshness performance. The relative importance of ride comfort is decreased to $0 \%$ by setting the weighting parameter $q_{1}$ as 0 . The relative importance of the harshness performance is increased gradually by changing the value of the weighting parameters $q_{2}, q_{3}$, and $q_{5}$ stepwise between 0.2 and 1 .

(3) Combined Ride Comfort and Harshness Optimization. The aim is to obtain the optimum damper top mount characteristics which provide a compromise between ride comfort and harshness. In this case, the relative importance of ride comfort and harshness is taken to be equal by setting the value of the weighting parameters $q_{1}, q_{2}, q_{3}$, and $q_{5}$ to 1 .

In the following sections, first the effect of the ride comfort and harshness weighting factors on the calculated optimal dynamic stiffness of the damper top mount is analyzed. Then, the optimal dynamic stiffness of the damper top mount together with the corresponding body vertical acceleration and top mount deformation is compared for three different optimization cases: optimal ride comfort, optimal harshness, and combined optimal performance.

\section{Optimization Results}

4.1. Weighting Parameter Analysis. The dynamic stiffness is a commonly used rubber mount characteristic which describes the relationship between the stiffness and the excitation frequency. The ride comfort and harshness performance of a vehicle are evaluated at different excitation frequency ranges. Therefore, the dynamic stiffness, which defines the change of rubber mount characteristics with frequency, is used to present the calculated optimal characteristics of the damper top mount.

Figure 11 shows the calculated optimum dynamic stiffness of the damper top mount as a result of the ride comfort optimization. As concluded in the parametric study by Kaldas et al. [16], the ride comfort of a vehicle improves with increasing damper top mount stiffness. The results of the optimization study also show that increasing the ride comfort weighting factor $q_{1}$ gradually from 0.2 to 1.0 leads to an increase in the calculated optimum damper top mount dynamic stiffness. However, the dynamic stiffness do not increase only in the ride comfort frequency range but also in the harshness frequency range, which in turn has a negative effect on the harshness performance of the vehicle.

Figure 12 shows the dynamic stiffness of the damper top mount calculated for the harshness optimization. The optimization process ends up with softer damper top mount characteristics in order to improve the harshness. However, the decrease of the top mount dynamic stiffness in the harshness frequency range is accompanied by a reduction of the dynamic stiffness in the ride comfort frequency range, leading to decrease in the ride comfort.

A comparison between each set of weighting parameters in terms of body vertical acceleration and damper top mount deformation is provided in Table 2. The minimum body acceleration RMS value is obtained during the ride comfort optimization with $q_{1}=1.0$. In addition to this, the damper top mount deformation RMS values obtained during the ride comfort optimization are lower than the top mount deformation RMS values obtained during the harshness optimization. This is due to the higher top mount dynamic stiffness resulting from the ride comfort optimization. The comfort oriented stiffer damper top mount helps also to reduce the peak-to-peak value of the top mount deformation during triangle cleat simulation.

The results presented above suggest that the body vertical acceleration RMS in the harshness optimization (with weighting factors $q_{2,3,5}=1.0$ ) is similar to the body acceleration RMS obtained with the nominal top mount characteristics. On the other hand, again for harshness optimization, the RMS of the top mount deformation reduces from $1.86 \mathrm{~mm}$ to $1.02 \mathrm{~mm}$; however this value is still higher than the top mount deformation RMS values obtained in all ride comfort optimization cases. Although the optimization process suggests softer dynamic stiffness to improve harshness performance, the resulting dynamic stiffness is still higher than the dynamic stiffness of the nominal top mount. This explains the improvement in the damper top mount deformation during the harshness optimization case for both stochastic and triangle cleat simulations. 
TABLE 2: Body vertical acceleration and damper top mount deformation during ride comfort and harshness optimization parameter variation.

\begin{tabular}{lcccc}
\hline $\begin{array}{l}\text { Optimization } \\
\text { set }\end{array}$ & $\begin{array}{c}\text { RMS } \\
\text { B.Acc. }\left(\mathrm{m} / \mathrm{s}^{2}\right) \\
\text { R\&H }\end{array}$ & $\begin{array}{c}\text { RMS } \\
\text { TMD }(\mathrm{m}) \\
\text { R\&H }\end{array}$ & $\begin{array}{c}\text { Peak-to-Peak B.Acc. } \\
\left(\mathrm{m} / \mathrm{s}^{2}\right)\end{array}$ & $\begin{array}{c}\text { Peak-to-Peak TMD } \\
\text { (m) }\end{array}$ \\
\hline Nominal & 1.4333 & 0.00233 & 13.5064 & 0.0152 \\
$q_{1}=1.0$ & 1.3946 & 0.00086 & 13.5949 & 0.0070 \\
$q_{1}=0.8$ & 1.3979 & 0.00086 & 13.5371 & 0.0071 \\
$q_{1}=0.6$ & 1.3992 & 0.00082 & 13.4852 & 0.0073 \\
$q_{1}=0.4$ & 1.4021 & 0.00080 & 13.4470 & 0.0073 \\
$q_{1}=0.2$ & 1.4055 & 0.00079 & 13.4024 & 0.0074 \\
$q_{2,3,5}=1.0$ & 1.4296 & 0.00186 & 13.6331 & 0.0133 \\
$q_{2,3,5}=0.8$ & 1.4221 & 0.00174 & 13.6344 & 0.0115 \\
$q_{2,3,5}=0.6$ & 1.4189 & 0.00155 & 13.6350 & 0.0109 \\
$q_{2,3,5}=0.4$ & 1.4130 & 0.00138 & 13.6353 & 0.0102 \\
$q_{2,3,5}=0.2$ & 1.4088 & 0.00102 & 13.6360 & 0.0091 \\
\hline
\end{tabular}

TABLE 3: Normalized optimum top mount characteristics.

\begin{tabular}{lcccrc}
\hline Optimization set & $K_{e 1}$ & $K_{e 2}$ & $K_{e 3}$ & $F_{\text {fr }_{\text {max }}}$ & $F_{d_{\text {scale }}}$ \\
\hline Nominal & 1.0000 & 1.0000 & 1.0000 & 1.0000 & 1.0000 \\
Optimum ride & 1.9691 & 1.0612 & 0.5875 & 1.9672 & 0.7313 \\
Optimum harshness & 1.2712 & 1.4456 & 0.6942 & 0.5180 & 0.5158 \\
Combined optimum & 1.2281 & 1.8306 & 0.8663 \\
\hline
\end{tabular}

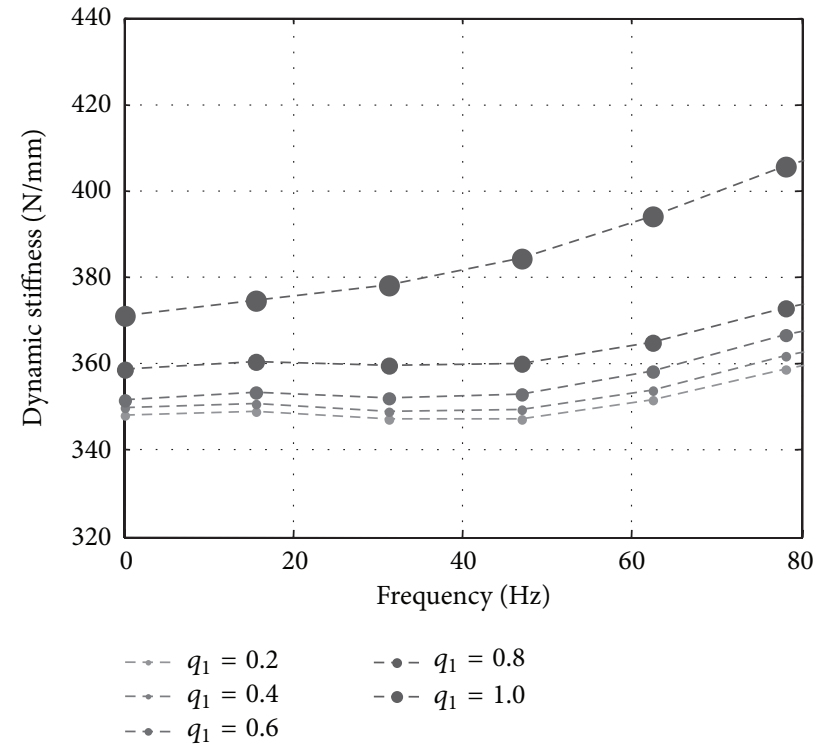

FIGURE 11: Change of top mount dynamic stiffness with ride comfort weighting.

4.2. Comparison of Ride, Harshness, and Combined Optimization Cases. As mentioned before, three different optimization cases for ride comfort, harshness, and combined ride comfort and harshness have been studied. The optimum ride comfort is obtained by setting the ride comfort weighting parameter $q_{1}$ to 1 and the harshness weighting parameters

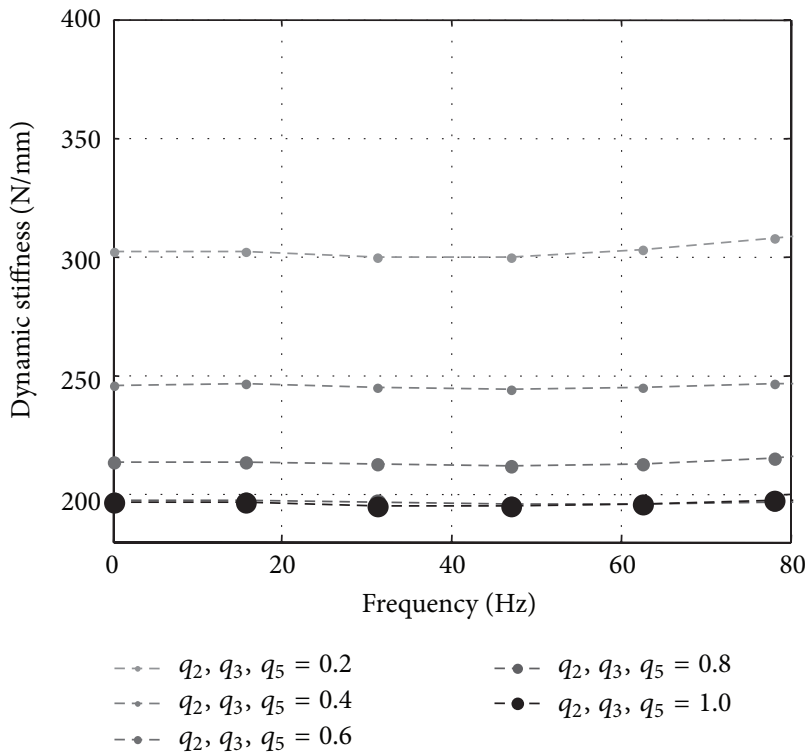

Figure 12: Change of top mount dynamic stiffness with harshness weighting.

$q_{2,3,5}$ to 0 , and vice versa for the optimum harshness performance. On the other hand, the optimum performance is obtained by setting all weighting parameters $q_{1,2,3,5}$ to 1 . The normalized optimum damper top mount characteristics for three different optimization cases are presented in Table 3.

Figure 13 presents the comparison between the damper top mount dynamic stiffness curves in the overall ride 
TABLE 4: Body vertical acceleration and damper top mount deformation for optimization cases.

\begin{tabular}{lcccc}
\hline $\begin{array}{l}\text { Optimization } \\
\text { set }\end{array}$ & $\begin{array}{c}\text { RMS } \\
\text { B.Acc. }\left(\mathrm{m} / \mathrm{s}^{2}\right) \\
\mathrm{R} \& \mathrm{H}\end{array}$ & $\begin{array}{c}\text { RMS } \\
\text { TMD }(\mathrm{m}) \\
\mathrm{R} \& \mathrm{H}\end{array}$ & $\begin{array}{c}\text { Peak-to-Peak B.Acc. } \\
\left(\mathrm{m} / \mathrm{s}^{2}\right) \\
\mathrm{IH}\end{array}$ & $\begin{array}{c}\text { Peak-to-Peak TMD } \\
(\mathrm{m})\end{array}$ \\
$\begin{array}{l}\text { Nominal } \\
\text { Optimum }\end{array}$ & 1.4333 & 0.00233 & 13.5064 & 0.0152 \\
$\begin{array}{l}\text { Ride } \\
\begin{array}{l}\text { Optimum } \\
\text { harshness }\end{array}\end{array}$ & 1.3946 & 0.00086 & 13.5949 & 0.0070 \\
$\begin{array}{l}\text { Combined } \\
\text { optimum }\end{array}$ & 1.4296 & 0.00186 & 13.6331 & 0.0133 \\
\hline
\end{tabular}

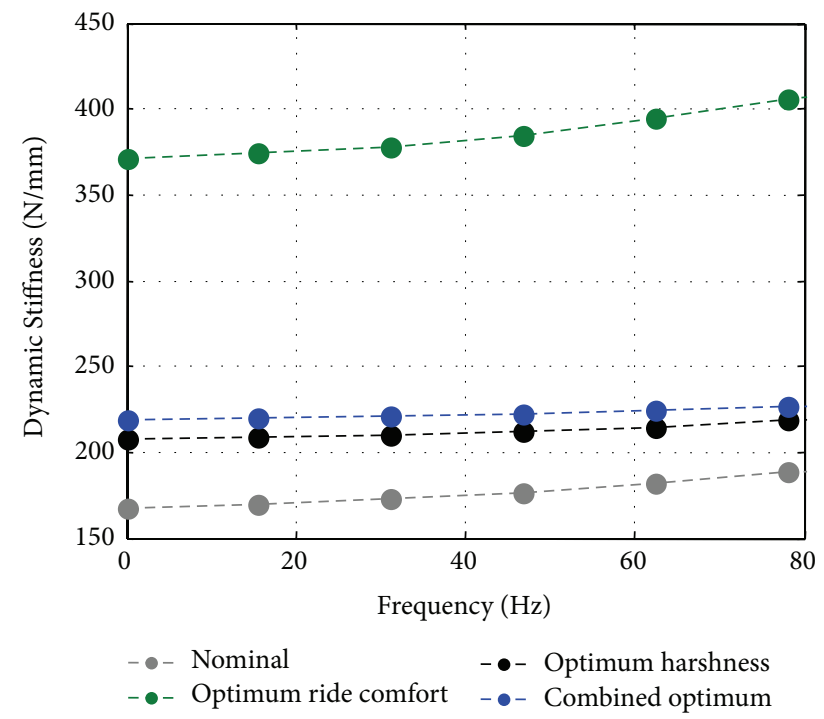

Figure 13: Dynamic stiffness of the damper top mount for different optimization cases.

comfort and harshness frequency range for the nominal, optimum ride comfort, optimum harshness, and combined optimum characteristics. The dynamic stiffness of the damper top mount increases gradually with excitation frequency. Higher damper top mount stiffness is favorable for the optimal ride comfort. Since the frequency range of interest in the ride comfort optimization is from 0 to $20 \mathrm{~Hz}$, the increase in the dynamic stiffness over $20 \mathrm{~Hz}$ is not regarded as a disadvantage in the optimization process. In contrast to the comfort optimization case, lower damper top mount stiffness is required for the optimum harshness performance. As already mentioned, the harshness performance considers only the frequencies above $20 \mathrm{~Hz}$. Therefore, the optimization routine tries keeping the dynamic stiffness low at all frequencies over $20 \mathrm{~Hz}$. This is however accompanied by a reduction in the dynamic stiffness also in the ride comfort frequency range.

Table 4 suggests that the proposed optimization routine is able to find an optimal set of damper top mount parameters which improve both ride comfort and harshness. The optimum characteristics, which provide a compromise between ride comfort and harshness, lead to a dynamic stiffness which is close to the dynamic stiffness of the optimum harshness case. This result is quite interesting since the ride comfort, harshness, and impact harshness performance criteria are included in the objective function with equal weightings for calculating the combined optimum characteristics. In order to explain this result, body acceleration and damper top mount deformation should be examined separately for the ride comfort and harshness frequency ranges. The RMS values in Table 4 cover the overall frequency range and, therefore, are not sufficient for a detailed analysis of the optimization results. In Figures 14 and 15, the power spectral density of the body acceleration and the damper top mount deformation at different frequency ranges are presented for different optimization cases.

Figures 14 and 15 show the comparison between the PSDs of the body vertical acceleration in the ride comfort and harshness frequency ranges for the nominal, optimum ride comfort, optimum harshness, and combined optimum top mount characteristics. The lowest body vertical acceleration level in the ride comfort frequency range, and especially around body resonance frequency, is obtained with the optimum ride comfort characteristics. On the other hand, the acceleration PSDs of the nominal, optimum harshness, and combined optimum cases in the ride comfort frequency are very close to each other. The top mount with optimum ride comfort characteristics leads to the highest body acceleration levels in the harshness frequency range, since a higher stiffness is imposed by the ride comfort optimization routine in order to reduce the body acceleration in the frequency range from $0 \mathrm{~Hz}$ to $20 \mathrm{~Hz}$. The optimization routine for the ride comfort does not consider the increase in the body vertical acceleration in the harshness frequency range as a disadvantage. Figures 14 and 15 also show that the combined optimum characteristics yield to a body acceleration response which is close to the one obtained by using the harshness optimized top mount characteristics, in both ride and harshness frequency ranges.

Deformation of the top mount must be constrained due to the space limitations of the vehicle suspension system. Low top mount stiffness values imposed by the optimization process can lead to high peaks in top mount deformation, especially around the body and wheel natural frequencies, which might violate the design constraints. The PSD of the damper top mount deformation in ride and harshness frequency ranges are presented in Figures 16 and 17. In all 


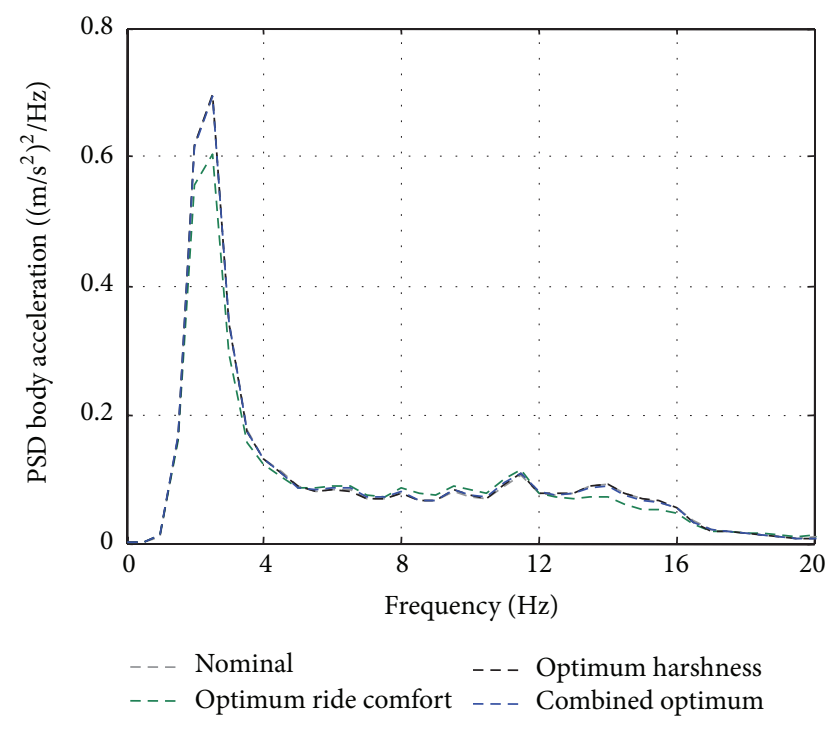

FIGURE 14: Body vertical acceleration in the ride comfort frequency range for different optimization cases.

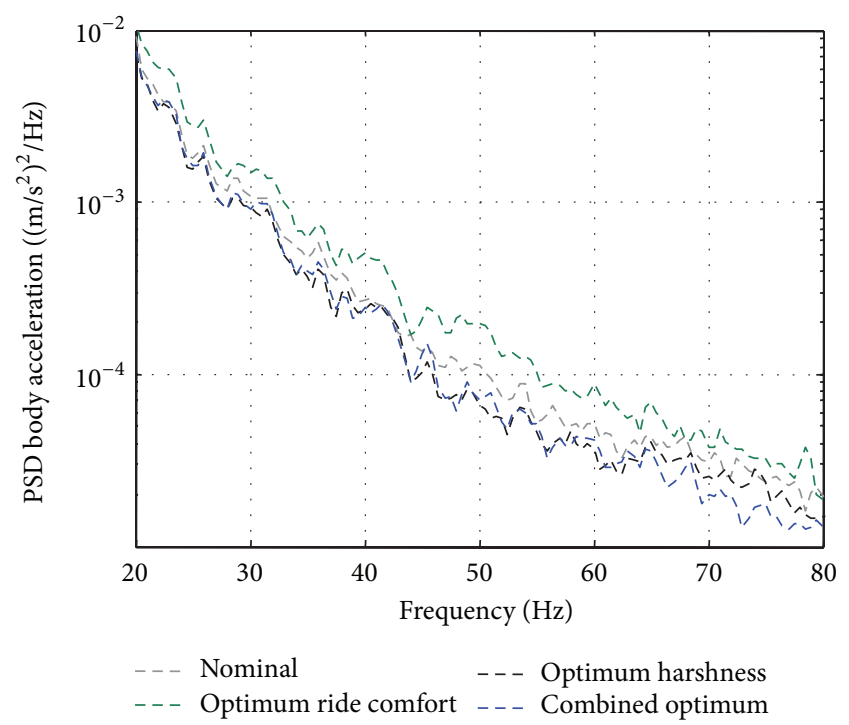

FIGURE 15: Body vertical acceleration in the harshness frequency range for different optimization cases.

optimization cases, the top mount deformation is clearly decreased with respect to the nominal characteristics. This is due to the higher dynamic stiffness values obtained in the optimization cases compared to the nominal characteristics. The damper top mount deformation reaches the lowest level with the optimum ride comfort characteristics since the optimal dynamic stiffness has the highest level for this case. As it was observed for the body acceleration, the top mount deformation obtained with combined optimum characteristics is close to the one obtained with optimum harshness characteristics.

As the vehicle crosses over the triangle road cleat presented in the previous sections, oscillations are observed in

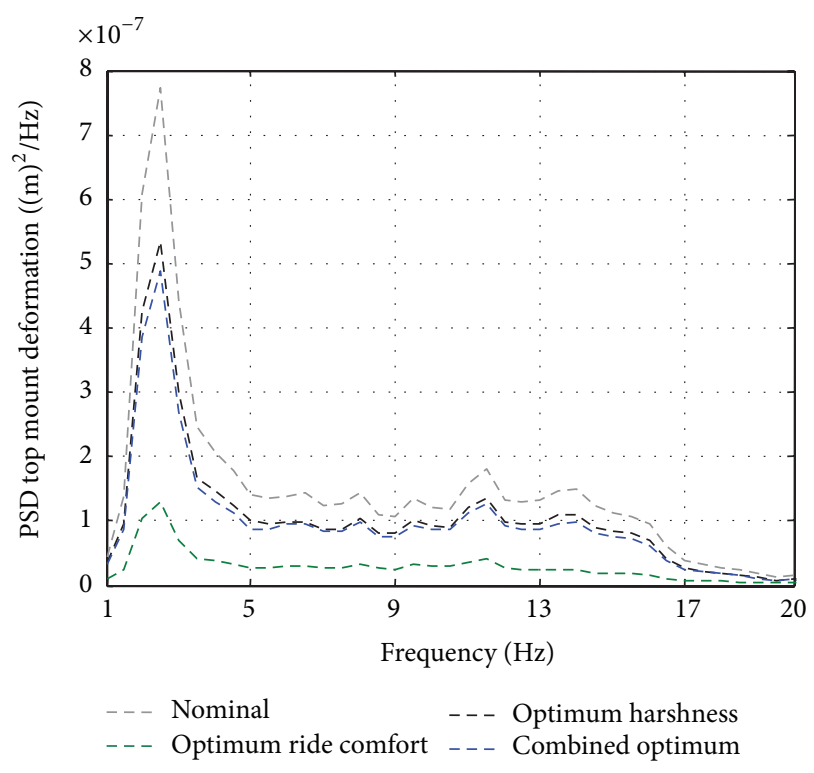

FIGURE 16: Damper top mount deformation in the ride comfort frequency range for different optimization cases.

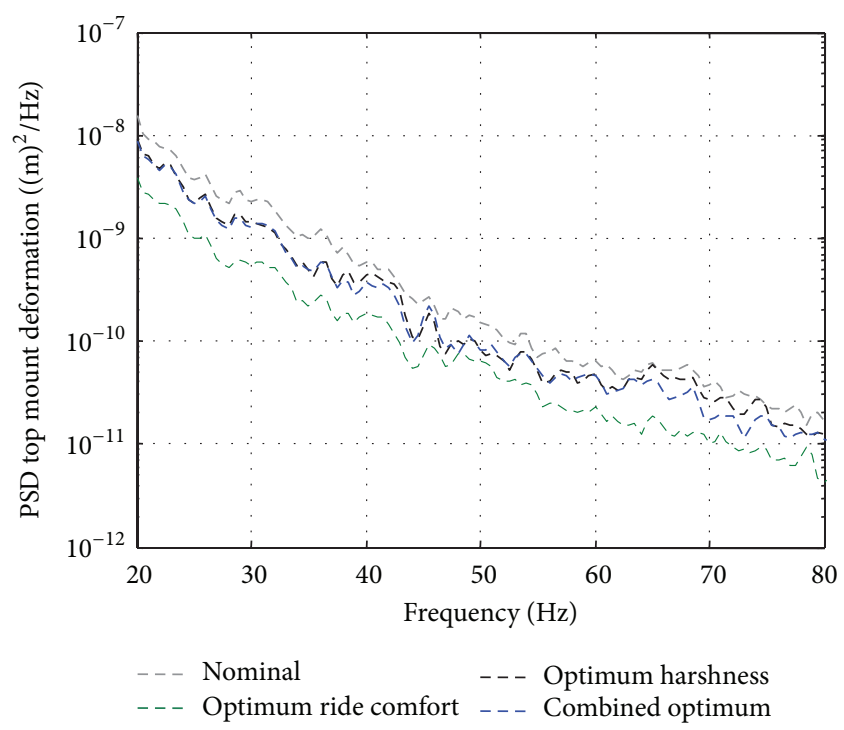

Figure 17: Damper top mount deformation in the harshness frequency range for different optimization cases.

the body acceleration and the damper top mount deformation. The performance of the suspension can be evaluated by considering the magnitudes of the acceleration peaks as the indication of the impact harshness. In addition to this, the peaks in damper top mount displacement are critical due to the space limitations. Therefore, the metric for the evaluation of $\mathrm{IH}$ is selected as the peak-to-peak values of body acceleration and damper top mount deformation. In order to improve the $\mathrm{IH}$, the sum of these two performance metrics (10) must be reduced.

Figure 18 presents the comparison between body vertical acceleration and damper top mount deformation during 


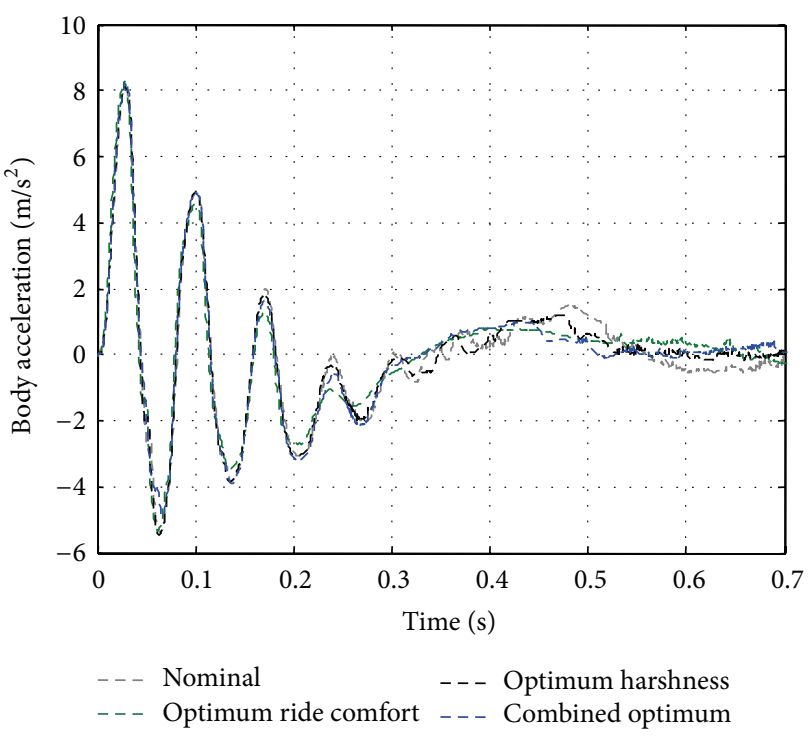

(a)

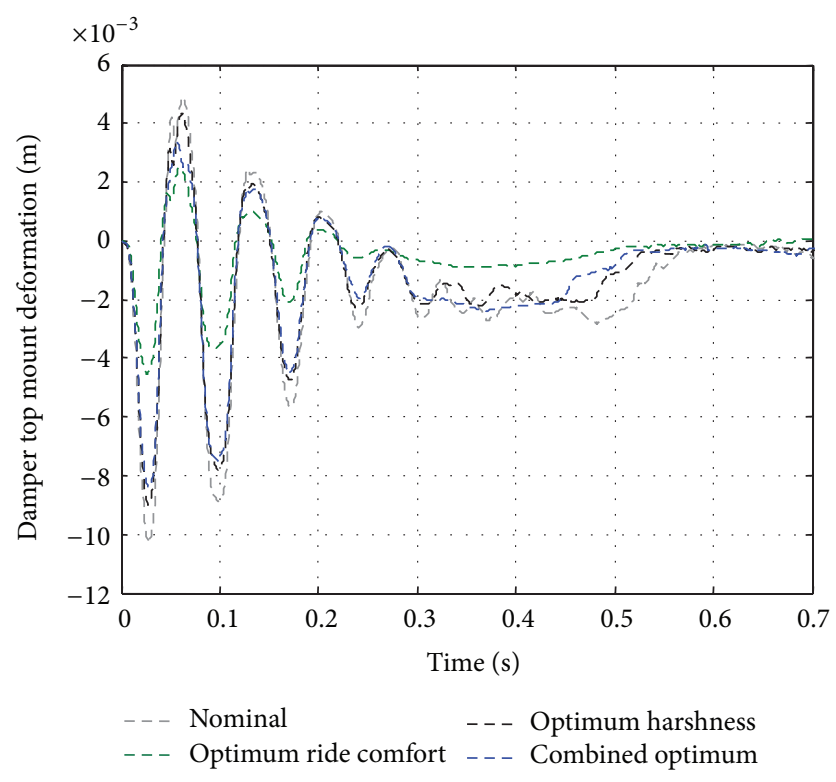

(b)

FIGURE 18: Body acceleration and damper top mount deformation during impact harshness event for different optimization cases.

the IH event for different top mount characteristics. No significant difference in the first (and the highest) peak-topeak of the body acceleration is observed between different optimization cases. After the first oscillation, lower body acceleration peaks are observed for the optimum ride comfort characteristics. In addition to this, the low frequency oscillations of the body acceleration are damped better with the optimum ride comfort and combined optimum characteristics.

The deformation of the damper top mount is expected to decrease with increasing top mount stiffness. As shown in Figure 18, the lowest damper top mount deformation is obtained with the optimal ride comfort characteristics, where top mount is stiffer in comparison with the other cases. Compared to the optimum harshness case, a slight decrease in the top mount deformation is obtained by using the combined optimum characteristics. It should be noted that the decrease in the top mount deformation is accomplished without increasing the body acceleration.

\section{Conclusion}

In this study, a new optimization methodology for optimizing the damper top mount characteristics to improve the vehicle ride comfort and harshness is presented. A combined objective function including the ride comfort, harshness, and impact harshness evaluations is developed and used within the optimization routine. Furthermore, a detailed damper top mount mathematical model is implemented inside a quarter vehicle model to provide accurate simulation results for the optimization study.

As the first stage of the optimization study, the influence of ride comfort and harshness weighting parameters of the objective function on the calculated optimal damper top mount characteristics is studied. The optimal damper top mount characteristics have been presented using dynamic stiffness curves. Furthermore, the influence of the objective function weighting parameters on vehicle ride comfort, harshness, and impact harshness is shown by using the RMS and peak-to-peak values of the vertical acceleration and damper top mount deformation. It is observed that increasing the ride comfort weighting parameter increases the calculated dynamic stiffness of the top mount. Contrarily, lower dynamic stiffness is obtained by using higher harshness weighting parameter. This suggests that a ride comfort oriented performance optimization leads to harder top mount characteristics, while softer damper top mount characteristics are imposed as a result of the harshness optimization.

The optimization results obtained by using the combined objective function with equal ride comfort and harshness weighting factors showed that the combined optimal top mount characteristics are closer to the optimum harshness characteristics. This is mainly due to the structure of the combined objective function proposed in this study. The combined objective function, with all weighting parameters set to one, includes only one ride comfort related component $(0-20 \mathrm{~Hz}$ acceleration RMS) but three harshness related components $(20-50 \mathrm{~Hz}$ and $50-80 \mathrm{~Hz}$ acceleration RMS, and peak-to-peak body acceleration). The idea behind having higher number of harshness performance components in the objective function is related to the roles of the damper and the damper top mount in the suspension system. The top mount is mainly responsible for isolating the body from high frequency excitations while the damper is responsible for the low frequency isolation. The task of the ride comfort component included in the proposed objective function is to guarantee that the selected top mount does not deteriorate the 
ride comfort. On the other hand, the three harshness related components in the objective function are related to the main task of the top mount in the suspension system.

\section{Notation}

\begin{tabular}{|c|c|}
\hline B.Acc.: & Body acceleration \\
\hline $\operatorname{Cost}_{(\mathrm{R} \& \mathrm{H})}$ : & $\begin{array}{l}\text { Cost function for the ride comfort and } \\
\text { harshness }\end{array}$ \\
\hline $\operatorname{Cost}_{\mathrm{IH}}$ : & Cost function for the impact harshness \\
\hline$C_{t}:$ & Tire damping coefficient \\
\hline TMD: & Top mount deformation \\
\hline$F_{\text {damping }}:$ & Damping force of the top mount \\
\hline$F_{\text {damper }}:$ & Damper force \\
\hline$F_{\text {elastic }}:$ & Elastic force of the top mount \\
\hline$F_{\text {friction }}:$ & Friction force of the top mount \\
\hline$F_{\mathrm{fr}_{\mathrm{max}}}:$ & Maximum friction force of the top mount \\
\hline$F_{\mathrm{fr}_{s}}:$ & The reference value of the state $F_{\text {friction }}$ \\
\hline$F_{\text {mount }}:$ & $\begin{array}{l}\text { Top mount force subjected to the vehicle } \\
\text { body }\end{array}$ \\
\hline$F_{\text {total }}:$ & $\begin{array}{l}\text { Total force generated from the damper } \\
\text { and top mount combination }\end{array}$ \\
\hline$F_{\text {viscous }}:$ & Viscous force of the top mount \\
\hline IH: & Impact harshness \\
\hline$K_{d}:$ & $\begin{array}{l}\text { Spring stiffness of the Maxwell element of } \\
\text { the top mount }\end{array}$ \\
\hline$K_{e 1}, K_{e 2}, K_{e 3}:$ & $\begin{array}{l}\text { Stiffness coefficients of the nonlinear } \\
\text { elastic element of the top mount }\end{array}$ \\
\hline$K_{s}:$ & Spring stiffness \\
\hline$K_{t}:$ & Tire stiffness \\
\hline$M_{b}:$ & Body mass \\
\hline$M_{w}:$ & Wheel mass \\
\hline Objective $_{\text {total }}$ : & The overall objective function \\
\hline PSDs: & Power spectral density \\
\hline$q_{1, \ldots, 6}:$ & Optimization weighting parameters \\
\hline$q_{1, \ldots, 6}^{n}:$ & $\begin{array}{l}\text { Weighting parameters normalization } \\
\text { factors }\end{array}$ \\
\hline$q_{1, \ldots, 6}^{*}:$ & Normalized weighting parameters \\
\hline RMS: & Root mean square \\
\hline $\mathrm{R} \& \mathrm{H}:$ & Ride comfort and harshness \\
\hline$S_{X_{b}-X_{k}}:$ & $\begin{array}{l}\text { Power spectral density of the top mount } \\
\text { deformation }\end{array}$ \\
\hline$S_{\ddot{X}_{b}}:$ & $\begin{array}{l}\text { Power spectral density of the body vertical } \\
\text { acceleration }\end{array}$ \\
\hline$x_{s}:$ & $\begin{array}{l}\text { The reference value of the state } x \text { for } \\
\text { friction element }\end{array}$ \\
\hline$X_{b}:$ & Vehicle body displacement \\
\hline$\ddot{X}_{b_{\max 1}}:$ & $\begin{array}{l}\text { Maximum positive peak of the body } \\
\text { vertical acceleration over triangle road } \\
\text { cleat }\end{array}$ \\
\hline$\ddot{X}_{b_{\min 1}}:$ & $\begin{array}{l}\text { Minimum negative peak of the body } \\
\text { vertical acceleration over triangle road } \\
\text { cleat }\end{array}$ \\
\hline$\left(X_{b}-X_{k}\right)_{\max }:$ & $\begin{array}{l}\text { Maximum positive peak of the top mount } \\
\text { deformation over triangle road cleat }\end{array}$ \\
\hline$\left(X_{b}-X_{k}\right)_{\min }:$ & $\begin{array}{l}\text { Minimum negative peak of the top mount } \\
\text { deformation over triangle road cleat }\end{array}$ \\
\hline
\end{tabular}

$X_{c}: \quad$ Displacement inside the Maxwell element of the top mount

$X_{\text {damper }}$ : Damper displacement

$x_{\mathrm{fr}}: \quad$ The parameter which determines how fast the friction force develops in relation to the displacement

$X_{k}$ : Damper connection displacement

$X_{\text {mount }}$ : Top mount displacement

$X_{o}: \quad$ Road input displacement

$X_{w}: \quad$ Wheel displacement

$\delta: \quad$ The ratio between the friction force and the maximum friction force.

\section{Conflict of Interests}

The authors declare that there is no conflict of interests regarding the publishing of this paper.

\section{References}

[1] B. Heißing and M. Ersoy, Chassis Handbook, Vieweg \& Teubner Verlag, Springer Fachmedien Wiesbaden GmbH, 1st edition, 2011.

[2] M. Blommer, S. Amman, P. Gu, P. Tsou, V. Dawson, and K. Vandenbrink, "Sound quality of impact harshness for light trucks and SUVs," SAE Paper 2003-01-1501, 2003.

[3] X. Yang and S. Medepalli, "Sensitivities of suspension bushings on vehicle impact harshness performances," Tech. Rep. 2005-010827, SAE Paper, 2005.

[4] L. Lingyang, Z. Yunqing, W. Shiwei, and C. Liping, "Optimization of suspension elastomeric bushing compliance under constraints of handling, ride and durability," SAE Paper 201001-0721, 2010.

[5] M. Aydın and Y. Ünlüsoy, "Optimization of suspension parameters to improve impact harshness of road vehicles," The International Journal of Advanced Manufacturing Technology, vol. 60, no. 5, pp. 743-754, 2012.

[6] P. Pintado and F. G. Benitez, "Optimization for vehicle suspension 1. Time domain," Vehicle System Dynamics, vol. 19, no. 5, pp. 273-288, 1990.

[7] J. M. Del Castillo, P. Pintado, and F. G. Benitez, "Optimization for vehicle suspension II. Frequency domain," Vehicle System Dynamics, vol. 19, no. 6, pp. 331-352, 1990.

[8] A. F. Naudé and J. A. Snyman, "Optimisation of road vehicle passive suspension systems. Part 1. Optimisation algorithm and vehicle model," Applied Mathematical Modelling, vol. 27, no. 4, pp. 249-261, 2003.

[9] A. F. Naudé and J. A. Snyman, "Optimisation of road vehicle passive suspension systems. Part 2. Qualification and case study," Applied Mathematical Modelling, vol. 27, no. 4, pp. 263274, 2003.

[10] M. J. Thoresson, P. E. Uys, P. S. Els, and J. A. Snyman, “Efficient optimisation of a vehicle suspension system, using a gradientbased approximation method, Part 1: mathematical modelling," Mathematical and Computer Modelling, vol. 50, no. 9-10, pp. 1421-1436, 2009.

[11] M. J. Thoresson, P. E. Uys, P. S. Els, and J. A. Snyman, "Efficient optimisation of a vehicle suspension system, using a gradientbased approximation method, Part 2: optimisation results," Mathematical and Computer Modelling, vol. 50, no. 9-10, pp. 1437-1447, 2009. 
[12] X. Yang, D. Zhang, S. Medapalli, and M. Malik, "Suspension tuning parameters affecting impact harshness performance evaluation," SAE Paper, no. 2006-01-0991, 2006.

[13] X. Wu, M. Farhad, and R. Sheets, "Designing suspensions to achieve desirable impact harshness and impact shake performance," SAE Paper, no. 2007-01-0585, 2007.

[14] J. Reimpel, H. Stoll, and Fahrwerktechnik:, Stoß-Und Schwingungsdämpfer, Vogel Verlag and Druck, Würzburg, Germany, 2nd edition, 1989.

[15] M. Kaldas, K. Çalışkan, R. Henze, and F. Küçükay, "Nonparametric modelling of damper top mounts," Proceedings of the Institution of Mechanical Engineers D, vol. 226, no. 6, pp. 740753, 2012.

[16] M. Kaldas, K. Çalışkan, R. Henze, and F. Küçükay, "The influence of damper top mount characteristics on vehicle ride comfort and harshness: parametric study," SAE International Journal of Passenger Cars-Mechanical Systems, vol. 5, no. 1, pp. 1-21, 2012.

[17] G. Klose, M. Bergman, and F. Küçükay, "MBS quarter vehicle test rig-influence of damper modelling on simulation quality," in FISITA World Automotive Congress, Budapest, Hungary, 2010.

[18] H. Kollmer, F. Küçükay, and K. Pötter, "Measurement and fatigue damage evaluation of road profiles in customer operation," International Journal of Vehicle Design, vol. 56, no. 1-4, pp. 106-124, 2011. 

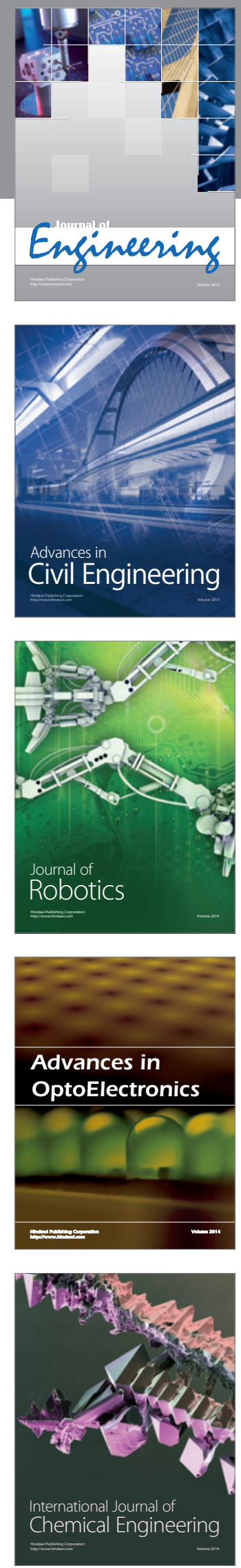

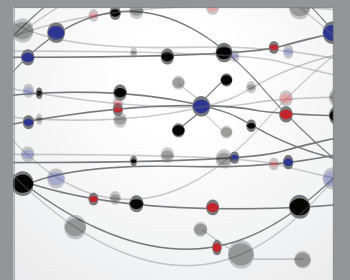

The Scientific World Journal
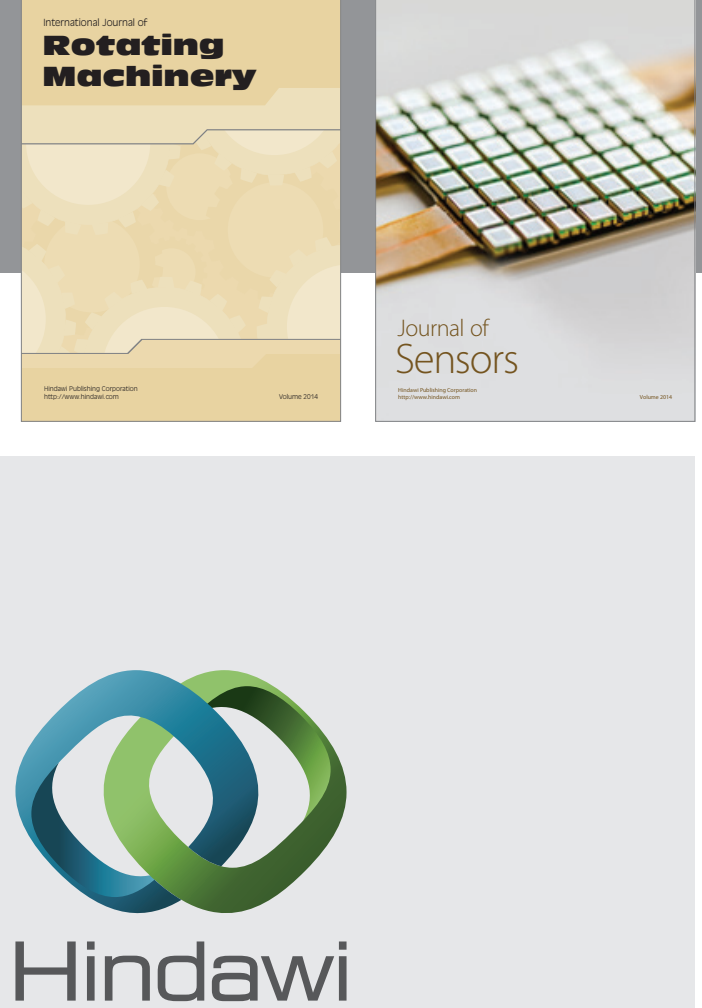

Submit your manuscripts at http://www.hindawi.com
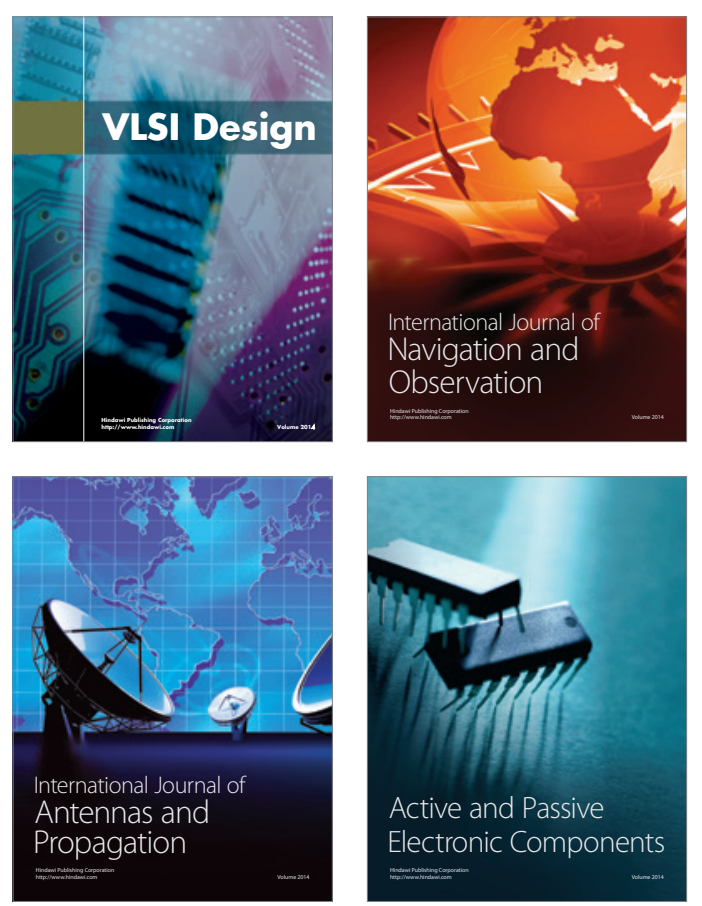
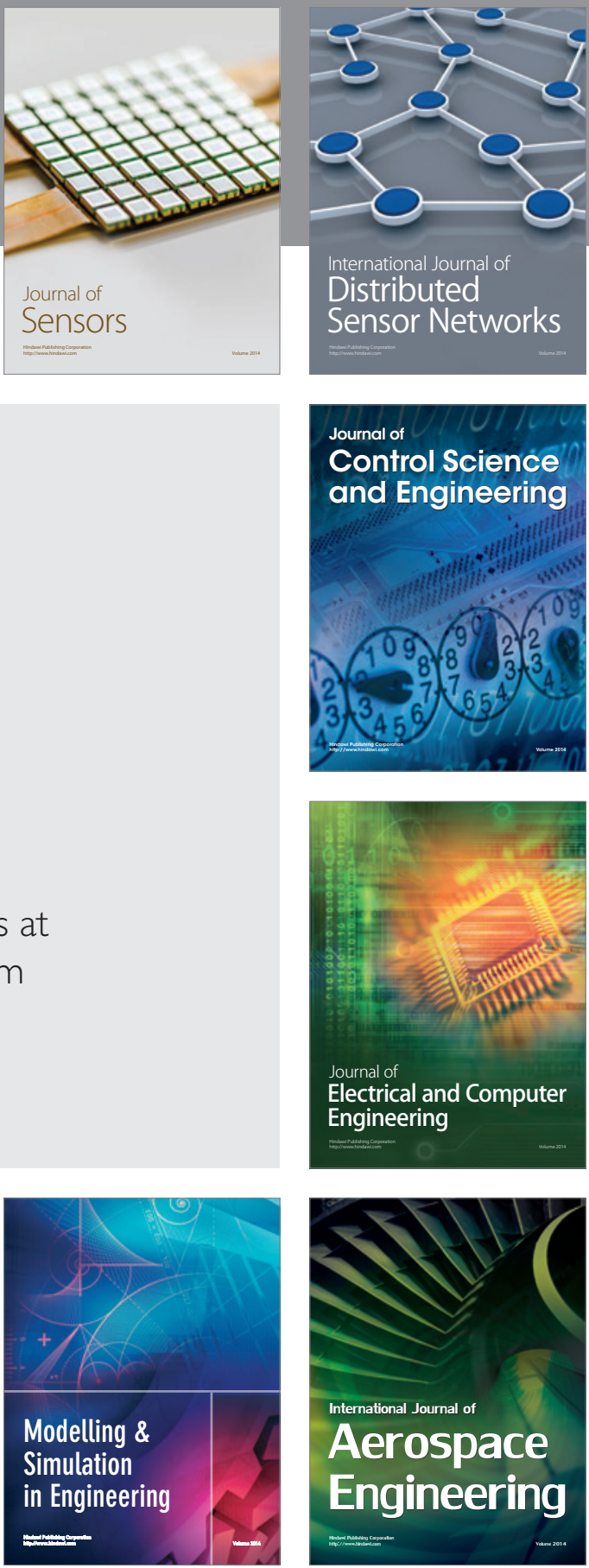

Journal of

Control Science

and Engineering
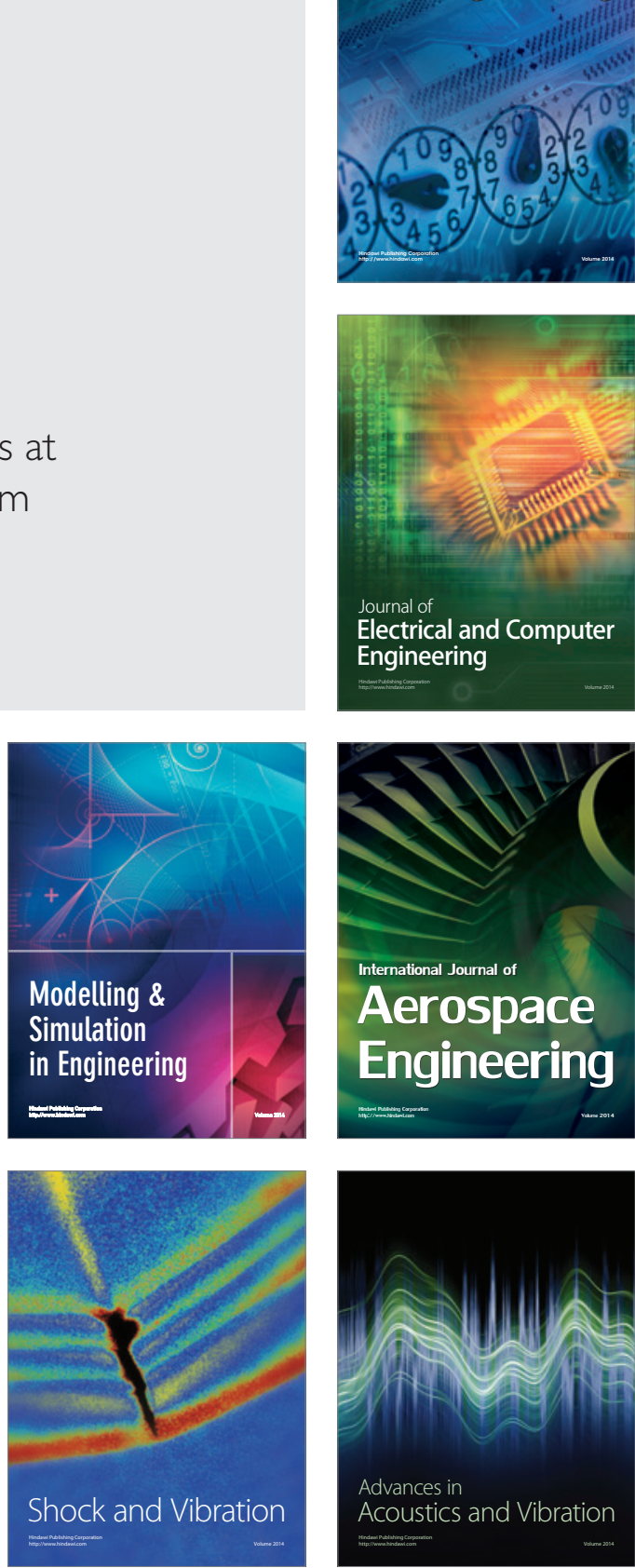